\title{
Through-the-scope self-expanding metal stent placement using newly developed short double- balloon endoscope for the effective management of malignant afferent-loop obstruction
}

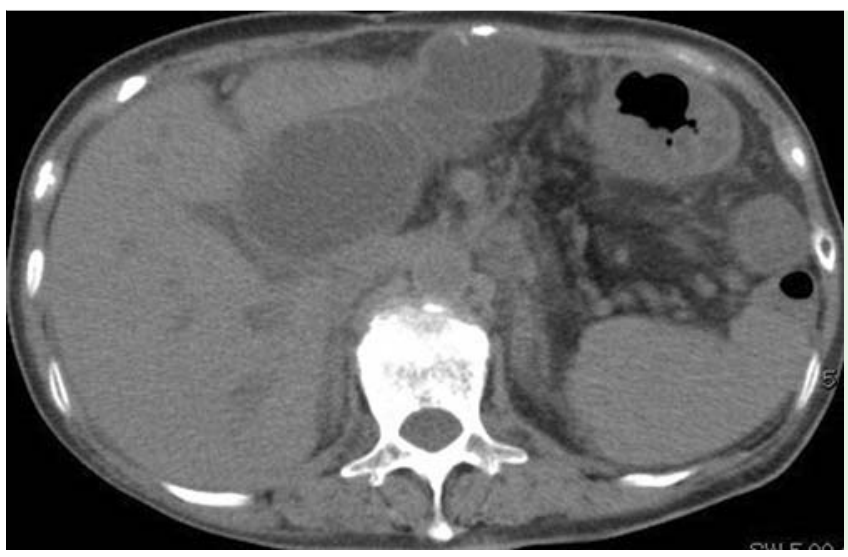

Fig. 1 Computed tomography scan revealed a dilated afferent loop.

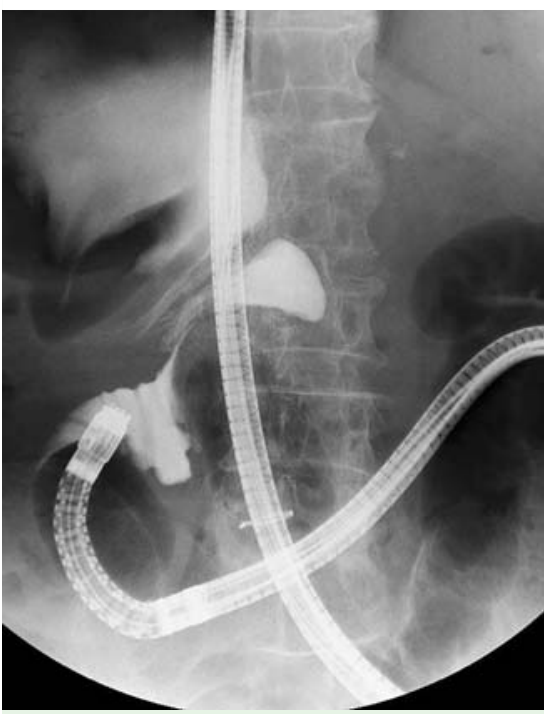

Fig. 3 Jejunography showed the stenotic lesion.

This is the first report of through-thescope (TTS) self-expanding metal stent (SEMS) placement, using a newly developed, short-type, double-balloon endoscope (S-DBE), for the palliation of malignant afferent-loop obstruction (ALO). The endoscope has a $3.2 \mathrm{~mm}$ working channel and $152 \mathrm{~cm}$ working length (EI-580BT; Fujifilm, Tokyo, Japan). The SEMS is a new Niti-S D pyloric/duodenal uncovered stent, with a diameter of $18 \mathrm{~mm}$ and lengths of $6 \mathrm{~cm}, 8 \mathrm{~cm}, 10 \mathrm{~cm}$, or $12 \mathrm{~cm}$, which is deployed using a $9 \mathrm{Fr} \times 220 \mathrm{~cm}$

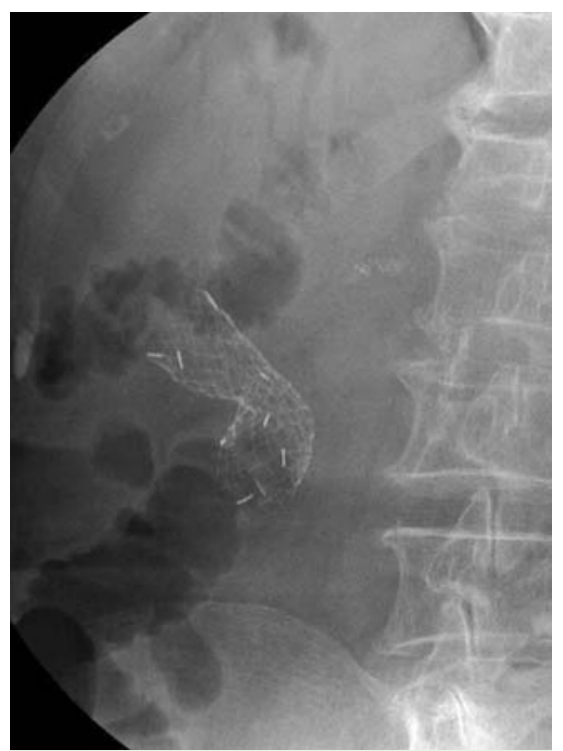

Fig.4 Improvement of afferent-loop obstruction was confirmed by abdominal radiography 2 days after the procedure.

delivery system (TaeWoong Medical Co., Ltd., Gimpo, South Korea). In the case presented here, the $6 \mathrm{~cm}$ SEMS was used. A 71-year-old woman, who had undergone pancreaticoduodenectomy for pancreatic cancer 5 years previously, was admitted for fever and acute abdominal pain. Computed tomography revealed dilation of the afferent loop, which was caused by bowel obstruction due to can-

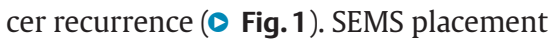
using the S-DBE was planned for palliation. S-DBE smoothly accessed the ALO

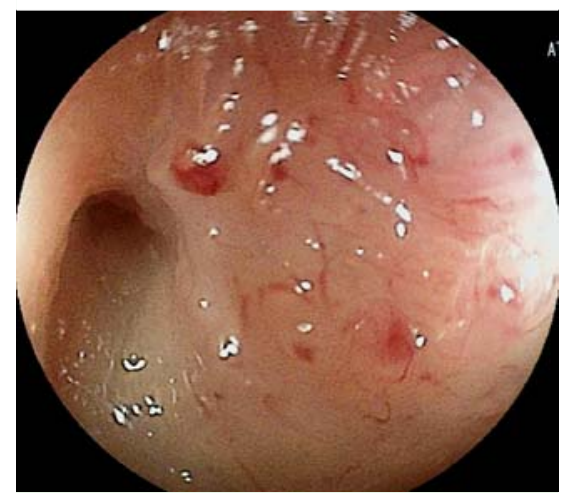

Fig. 2 Malignancy of the afferent-loop obstruction was confirmed by endoscopy.

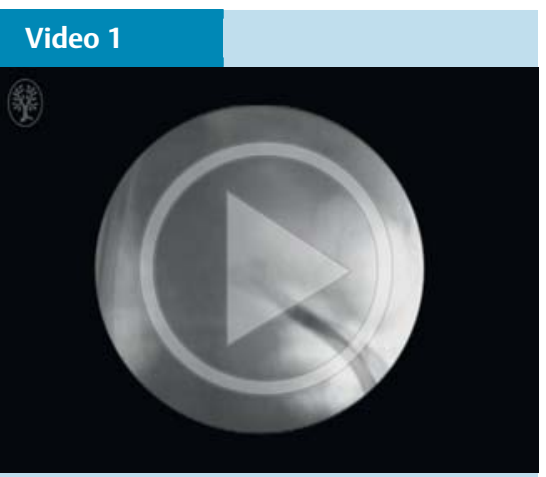

Afferent-loop obstruction was confirmed by endoscopic view. An endoscopic retrograde cholangiopancreatography catheter was used to pass the guidewire through the stenotic region. Through-the-scope self-expanding metal stent placement was performed along the guidewire. Endoscopic view confirmed good drainage function and the fluoroscopic image confirmed stent deployment.

lesion. Malignancy was confirmed from the endoscopic view ( $\bullet$ Fig. 2), and the stenosis was recognized on the jejunograph ( $\bullet$ Fig. 3 ).

The SEMS was advanced through the S-DBE and deployed accurately at the target area under direct endoscopic view. TTS SEMS placement was successful, and immediate intestinal flow was confirmed visually ( $\bullet$ Video 1 ). Abdominal radiography 2 days after the procedure showed a palliated ALO ( $\bullet$ Fig.4). The patient started dietary intake 3 days after the pro- 
cedure and was discharged without any complication.

The combined use of the new S-DBE with $3.2 \mathrm{~mm}$ working channel and SEMS with the $9 \mathrm{Fr}$ delivery system enabled TTS SEMS placement, which had previously been difficult because the large diameter of the SEMS delivery system did not allow stent deployment through the $2.8 \mathrm{~mm}$ working channel of conventional short DBE.

Malignant ALO caused by pancreatic cancer recurrence after pancreaticoduodenectomy is usually managed by percutaneous transhepatic drainage [1] or palliative surgical bypass $[2,3]$; however, these are invasive procedures and can only be performed in a limited selection of patients.

Recent reports have described SEMS placement for ALO via a DBE overtube [4, 5]; however, stent deployment was attempted only under fluoroscopic view. Therefore, TTS SEMS placement is an important innovation for the management of malignant ALO because it allows safe and accurate SEMS placement.

Endoscopy_UCTN_Code_TTT_1AP_2AD

Competing interests: None
Masaaki Shimatani, Makoto Takaoka, Mitsuo Tokuhara, Kota Kato, Hideaki Miyoshi, Tsukasa Ikeura, Kazuichi Okazaki

Third Department of Internal Medicine, Kansai Medical University, Osaka, Japan

\section{References}

1 Yao NS, Wu CW, Tiu CM et al. Percutaneous transhepatic duodenal drainage as an alternative approach in afferent loop syndrome with secondary obstructive jaundice in recurrent cancer. Cardiovasc Intervent Radiol 1998; 21: 350-353

2 Pannala R, Brandabur JJ, Gan SI et al. Afferent limb syndrome and delayed GI problems after pancreaticoduodenectomy for pancreatic cancer: single-center, 14-year experience. Gastrointest Endosc 2011; 74: 295 302

3 Hosono S, Ohtani H, Arimoto $Y$ et al. Endoscopic stenting versus surgical gastroenterostomy for palliation of malignant gastroduodenal obstruction: a meta-analysis. J Gastroenterol 2007; 42: 283-290

4 Sasaki $T$, Isayama $H$, Kogure $H$ et al. Doubleballoon enteroscope-assisted enteral stent placement for malignant afferent-loop obstruction after Roux-en-Y reconstruction. Endoscopy 2014; 46 (Suppl. 01): E541 - 542

5 Shimatani M, Fukata N, Suzuki R et al. Small bowel intervention and application of enteroscopy for altered small bowel anatomy - endoscopic advanced therapy using double balloon enteroscopy. Gastrointest Interv 2014; 3: 69-74
Bibliography

DoI http://dx.doi.org/ 10.1055/s-0041-111503

Endoscopy 2016; 48: E6-E7

(C) Georg Thieme Verlag KG

Stuttgart · New York

ISSN 0013-726X

\section{Corresponding author}

\section{Masaaki Shimatani, MD}

Third Department of Internal Medicine Kansai Medical University

2-5-1 Shinmachi

Hirakata

Osaka 573-1010

Japan

Fax: +81-72-8042524

shimatam@hirakata.kmu.ac.jp 